\title{
The Impact of Climate Variabilities on the Water Resources of Nyong River (Cameroon) during Few Anterior Decades
}

\author{
Mpakam Hernanie Grelle1, Ombolo Auguste1, Samba Assomo Philippe ${ }^{2 *}$, \\ Bineli Ambomo Etienne ${ }^{1}$ \\ ${ }^{1}$ The Higher Institute of the Sahel, University of Maroua, Maroua, Cameroon \\ ${ }^{2}$ Faculty of Science, University of Yaoundé I, Yaounde, Cameroon \\ Email: "sambafilipe@yahoo.fr
}

Received 9 March 2016; accepted 16 April 2016; published 19 April 2016

Copyright (C 2016 by authors and Scientific Research Publishing Inc.

This work is licensed under the Creative Commons Attribution International License (CC BY).

http://creativecommons.org/licenses/by/4.0/

(c) (i) Open Access

\begin{abstract}
The Nyong River is situated in south Cameroon. The study of the impact of climate change on the water resource of the River shows that its precipitations and flow rate are decreasing. This negative effect is reinforcing by the fact that the water of the River is collected to feed the population of Yaoundé, the political capital of Cameroon and its environs. Given that no action can stop the variability of climate factors, it is necessary to ameliorate the management of water resource of Nyong River.
\end{abstract}

\section{Keywords}

Climate Variability, Water Resource, Nyong River, Impact

\section{Introduction}

The phenomenon of climate change is now a reality because of its impact in many domains of our life. The global change can easily be observed throw the increasing of temperature on the surface of earth, the melting glacial ice, the displacement of seasons, the disturbing on rain events...many others studies show that natural resources are all in danger (flora, fauna, water, human life...). The humanity is fearing now the negative impact that induces global change. The important task of expert is today to call the attention of the humanity on the management of the natural resources that are subjected to disappearing, important reducing or the lost in quality. The same attention may be reserved on the constructions of others infrastructures by looking for new standards

*Corresponding author.

How to cite this paper: Grelle, M.H., Auguste, O., Philippe, S.A. and Etienne, B.A. (2016) The Impact of Climate Variabilities on the Water Resources of Nyong River (Cameroon) during Few Anterior Decades. International Journal of Geosciences, 7, 459-469. http://dx.doi.org/10.4236/ijg.2016.74035 
that can face the impact of climate change. The example of the water resource of river Nyong can be taken as the case study of the impact of climate change on the natural resource. The main objective of the paper is to present the evolution of rain events in the Nyong basin and the flow rate of the river related to climate change.

\section{Presentation of Study Field}

The basin of Nyong River with $27,800 \mathrm{Km}^{2}$ of area is situated in central Africa in southern forest ecosystem of Cameroon (Figure 1). It extends from $2^{\circ} 48^{\prime}$ to $4^{\circ} 32^{\prime}$ LatN and from $9^{\circ} 54^{\prime}$ to $13^{\circ} 30^{\prime}$ Long Est [1]-[3]. It is limited in North by Sanaga basin, in east by a part of Congo basin, in west by AtlanticOcean and by Ntem basin in south. The tables below (Table 1 and Table 2) present the characteristics of the stations that have been chosen.

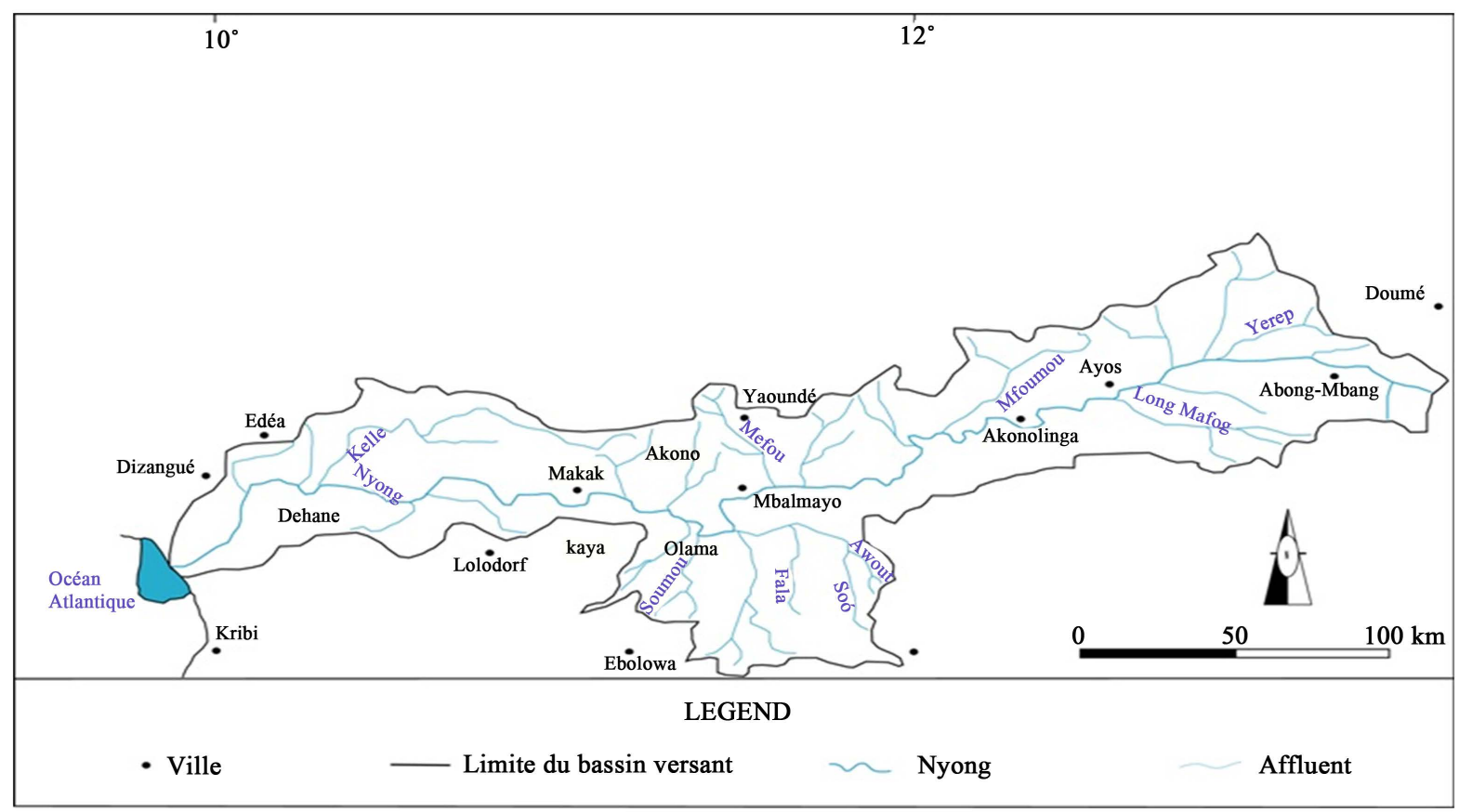

Figure 1. Presentation of the Nyong basin.

Table 1. Characteristics of rainfall stations of Nyong.

\begin{tabular}{|c|c|c|c|c|c|}
\hline \multirow{2}{*}{ Stations } & \multicolumn{2}{|c|}{ Coordinatess } & \multirow{2}{*}{$\begin{array}{l}\text { Altitude } \\
\text { (m) }\end{array}$} & \multirow{2}{*}{ Period } & \multirow{2}{*}{$\mathrm{n}$} \\
\hline & Latitude Nord & Longitude Est & & & \\
\hline Abong-Mbang & $03^{\circ} 59^{\prime}$ & $13^{\circ} 10^{\prime}$ & 657 & 1939-2006 & 68 \\
\hline Akonolinga & $03^{\circ} 47^{\prime}$ & $12^{\circ} 15^{\prime}$ & 643 & 1934-2006 & 73 \\
\hline Yaoundé & $03^{\circ} 51^{\prime}$ & $11^{\circ} 30^{\prime}$ & 760 & 1929-2006 & 78 \\
\hline Eséka & $03^{\circ} 41^{\prime}$ & $10^{\circ} 42^{\prime}$ & 146 & $1936-2006$ & 71 \\
\hline Sangmélima & $02^{\circ} 56^{\prime}$ & $11^{\circ} 59^{\prime}$ & 713 & 1934-2006 & 73 \\
\hline
\end{tabular}

Table 2. Characteristics of hydrometric stations of Nyong.

\begin{tabular}{|c|c|c|c|c|c|c|}
\hline \multirow{2}{*}{ Stations } & \multicolumn{2}{|c|}{ Coordinatess } & \multirow{2}{*}{ Altitude (m) } & \multirow{2}{*}{ Area $\left(\mathrm{km}^{2}\right)$} & \multirow{2}{*}{ Period } & \multirow{2}{*}{$\mathrm{n}$} \\
\hline & North Latitude & East Longitude & & & & \\
\hline Mbalmayo & $03^{\circ} 31^{\prime}$ & $11^{\circ} 30^{\prime}$ & 634 & 13555 & 1951-1977 and 1998-2006 & 32 \\
\hline Olama & $03^{\circ} 26^{\prime}$ & $11^{\circ} 17^{\prime}$ & 628 & 18510 & 1965-1977 and 1998-2006 & 18 \\
\hline
\end{tabular}




\section{Methodology}

Several methods have been used by those that focused on estimates of average rainfall and flow rates or to the study of climate variability and climate change.

\subsection{A method for Estimating Average Rainfall and Average Flows in the Watershed}

\subsubsection{Estimation of Average Rainfall}

To calculate the average rain fell on a watershed, three methods are applicable to rainfall data:

- the arithmetic average method that calculates the arithmetic average of precipitation amount recorded in the same period of time for various stations of the basin. In the absence of a large number of observation posts, this method is not very recommended because it may give too much importance to extremes. It is given by the formula

$$
P_{\text {moy }}=\frac{\sum_{1}^{n} p_{i}}{n},
$$

$p_{i}=$ rainfall.

$n=$ number of rainfall stations.

- Thiessen method that attaches a weighting factor to each gauge.

The stations are plotted on a map and joined together by a straight line. The mediators segments determine a polygon around each station. The sides of the polygons and the watershed line represent the boundaries of the area given to each station. The area $A_{i}$ of each polygon is determined by planimetry. The weighted average precipitation for the basin $P_{o}$ is calculated as the sum of precipitation for each station $P_{i}$ multiplied by its weight (Aiarea) and then divided by the sum of the total area $A$ of the basin. Thiessen method is one that has been used in the framework of this work, using the formula:

$$
P_{o}=\frac{\sum A_{i} P_{i}}{A}
$$

- Isohyets method is based on the map of isohyets. The calculation of the average rainfall is therefore firstly to calculate (in $\mathrm{m}^{2}$ ) and planimetry of the partial surface $S_{1}$ of the basin between two successive isohyets $P_{1}$ and $P_{2}$. Having admitted that the height of rainfall this elementary surface is equal to the arithmetic average of the two curves that limit $\left(P_{1}+P_{2}\right) / 2, P_{i}$ Precipitation is then calculated across this section by elementary rainfall

$$
P_{i}=\left(\frac{p_{1}+p_{2}}{2}\right) S_{1}
$$

The same process is repeated step by step for each band circumscribed by two consecutive isohyets. The average water blade fell on the basin is equal to the quotient of the sum of precipitation rainfall elementary surfaces by the total area of the basin.

\subsubsection{Estimation of Flow Rates}

To estimate flow rates, in general we follow the following steps:

We choose a section of the river for the implementation of the hydrometric station which is equipped with the following (installation of staff gauges),

An observer is hired to read the water levels twice daily (6 am and $18 \mathrm{pm})$. A series of discharge measurements is then carried throughout the hydrological cycle. There are basically three types of gauging:

- Tonnage reel that is most used. It is to explore the velocity fields in a section through which we want to measure liquid flow. The measuring section here should be perpendicular to the liquid streams, themselves parallel to each other.

- Gauging the float.

- The chemical gauging.

The height of a river is the height of the water surface relative to a reference dimension. Water levels are achieved thanks to the staff gauge readings installed at the station and they are transformed into flows (indirect method of determining the flow of a river) by means of software developed TIDHYP the CRH/IRGM whose operating principle is based on a function establishing a relationship between the water level and flow: $Q=f(H)$. This relationship represents the rating curve (or standard curve) established from the discharge measurements 
made at the station. The sum of the daily flows for each month divided by the number of days gives the average monthly flow; the sum of the daily flows for every day of the year is divided by 365 to get the mean annual flow.

\subsection{Method of Variability and Climate Change}

The analysis processes of climate changes using methods based on the stationarity test of time series measurements and research segmentation statistically different sequences. These methods have been successfully applied on series of rainfall and flows in Africa and Europe [4]-[6]. To eliminate the internal variability of each unit, analyzes often focus on standardized values (indices) that measure a deviation from an average basis over a long period. The segmentation method of [7] or the test Pettit [8], are frequently used to detect ruptures in rainfall pattern or flow.

\subsection{Calculation Principle of the Low-Pass Filter Hanning Order 2}

The method of the low-pass filter of order 2 or Hanning weighted moving averages method was used to weight the rainfall totals. Indeed, the non-recursive low-pass filter Hanning 2nd order filters the seasonal variations by calculating weighted rainfall totals. Its principle of calculation encompasses both different formulas depending on the position of the year for which the weighted moving average is calculated in the series and it is the following:

$$
P_{t}=0.06 X_{t-2}+0.25 X_{t-1}+0.38 X_{t}+0.25 X_{t+1}+0.06 X_{t+2}
$$

where: $3 \leq t \leq(n-2)$;

$X_{t-2}, X_{t-1}$ : rainfall totals observed the first two terms prior to the end $X_{t}$;

$X_{t+2}, X_{t+1}$ : rainfall totals observed the first two terms following the end $X_{t}$.

The weighted rainfall totals for the first two $\left(P_{1}, P_{2}\right)$ and the last two.

$\left(p_{n-1}, p_{n}\right)$ terms of the series are calculated using the following expressions (n: size of the series):

$$
\begin{gathered}
P_{1}=0.54 X_{1}+0.46 X_{2} ; \\
P_{2}=0.25 X_{1}+0.5 X_{2}+0.25 X_{3} ; \\
P_{n-1}=0.25 X_{n-2}+0.5 X_{n-1}+0.25 X_{n} ; \\
P_{n}=0.54 X_{n}+0.46 X_{n-1}
\end{gathered}
$$

To better visualize periods of deficit and excess rainfall, moving averages were centered and reduced according to the following calculation of indices.

\subsection{Calculation of Hydro Rainfall Indices}

The indices studied here measure the differences between the variables studied over an average basis over a long period. They can differentiate the dry years or decades/loss and wet/surplus.

Indices of annual rains or annual rates are calculated according to the formulas proposed by

Nicholson in [9]:

$$
X_{i j}=\left(P_{i}-m_{i}\right) / S_{i}
$$

Where $P_{i}$ is the annual rain height (average annual rate) of station $i$;

$m_{1}$ is the interannual average rain (or flow )to the station i on the reference period;

If is the standard deviation of annual rainfall (or annual rates).

$X_{i j}$ is the annual average index of rainfall or flow in the station $i$ for year $j$.

To maintain the statistical index homogeneity, the indices are calculated for all variables studied on a uniform reference period [10].

\subsection{Break Detection Tests in Rainfall Series}

To detect the break in the time series, the IRD has developed the software khronostat. This software includes the verification tests of randomness of the sample that are the test Brushand, the ellipse of wood, non-parametric method of Pettit, the method of [6]; only the last two methods will be explained and used in this work. 


\subsection{Segmentation Method of Hubert}

The time series segmentation procedure proposed by [6] is appropriate in search of multiple changes of the average. It provides the means of a specific algorithm one or more termination date between adjacent segments, the averages are significantly different.

\subsection{Pettit Test Principle}

The principle of the test Pettit is to divide the series studied ( $\mathrm{N}$ effective) in two sizes of $\mathrm{m}$ and $\mathrm{n}$ sub-samples respectively. We then calculate the sum of the ranks of each subsample elements in the total sample. A statistical analysis is then performed from both the amounts so determined, then it is tested under the assumption of no belonging in two samples from the same population.

Pettit test is nonparametric and derives from that of Mann Whitney. The absence of break in the series (XI) of size $N$ is the null hypothesis. Its implementation implies that for any time $T$ between 1 and $N$, the time series $\left(X_{i}\right) i-1$ at $t$ and $t+1$ to $N$ are from the same population. The test variable is the maximum absolute value of the variable $U_{t, N}$ defined by :

$$
U_{t, N}=\sum_{i=1}^{t} \sum_{i=t+1}^{N} D_{i j} \quad D_{i j}=\operatorname{Sgn}\left(X_{i}-X_{j}\right) \text { with } \operatorname{sgn}(x)=1 \text { si } x>0,0 \text { and }-1 \text { si } x<0
$$

If the null hypothesis is rejected, an estimate of the date of termination is given by the moment defines the maximum absolute value of the variable $U_{t, N}$.

Rainfall or hydrometric series and subjected to the test of Pettit indicate the great periods of change in rainfall or flow rates. The break can be defined as the point at which a change occurs in the time series [9].

\subsection{Determination of Rainfall or Hydrological Deficit}

This method determines the percentage of variation of the deficit of the series (rain, flow) in a period Ti around the time $T$ considered. For hydro-rainfall time series variables present a break, this method specifies the percentage change in the average around the date of termination and is obtained by the following formula: [11]

$$
D=\frac{X_{j}}{X_{i}}-1
$$

with:

$x_{i}$ : average for the period after the break.

$x_{i}$ : Average for the period before failure. riod.

This method can also monitor changes in precipitation and discharge over time on a predefined reference pe-

These methods are applied to each of the rainfall and hydrometric series in the studies of climate variability. However, many studies in Africa and elsewhere through the test of Pettit and the calculation of indices demonstrate their robustness for detecting breaks in time series, therefore, these methods will be used in further work to analyze fluctuations hydrometric watershed of Nyong.

\section{Presentation and Interpretation of Results}

\subsection{Temporal Evolution of the Rain}

The analysis of annual rainfall stations Eseka, Sangmélima, Akonolinga, Yaoundé, Abong-Mbang and two subbasins studied reveals a general decline in precipitation in the Nyong basin.

The difference in the slopes of the lines that give the general trend of precipitation in the stations shows that all stations are not affected to the same extent of the deficit and the decline is not uniform.

The analysis of annual variations in rainfall and changes in annual rainfall indices for the reference period 19402006 show three climatic periods.

- A normal period of 1940-1962 with oscillations around the mean,

-A wet period of 1963-1975,

- From 1976, a period deficit with some surplus years (1984, 1985, 1990, 1993 and 2001).

The general trend of right rainfall which gives the sense of the evolution of annual rainfall is decreasing (Figure 2). 


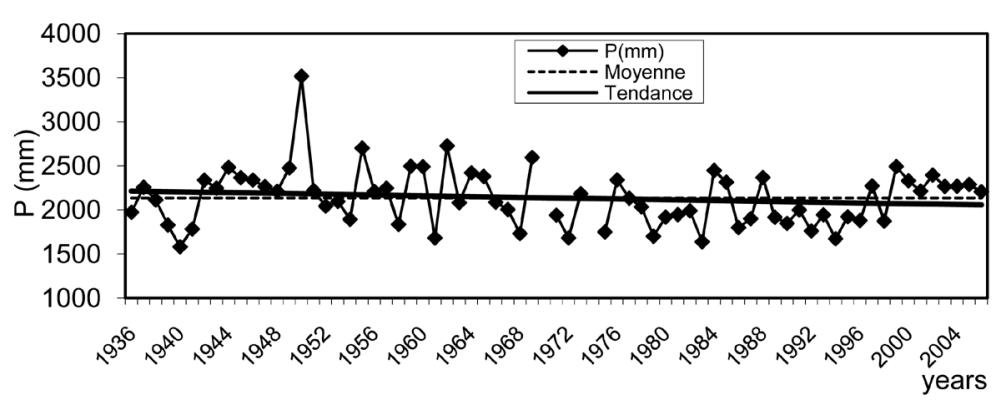

(a)

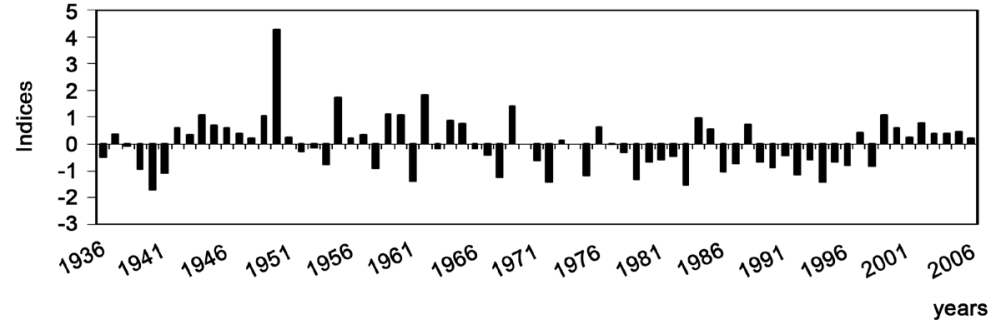

(b)

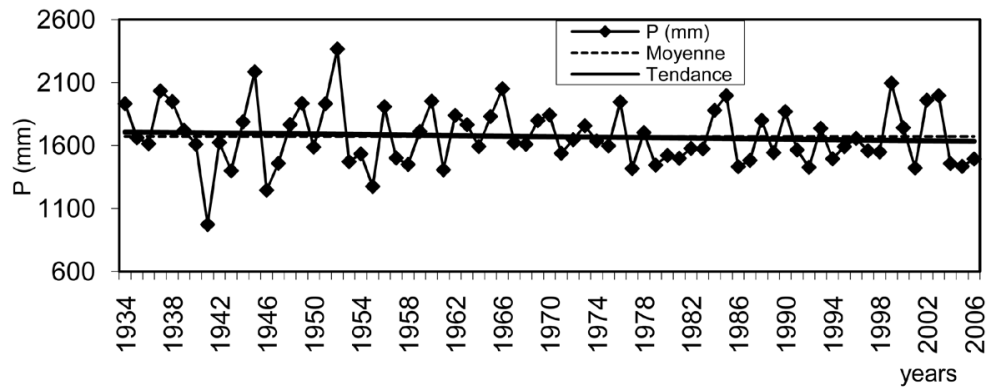

(c)

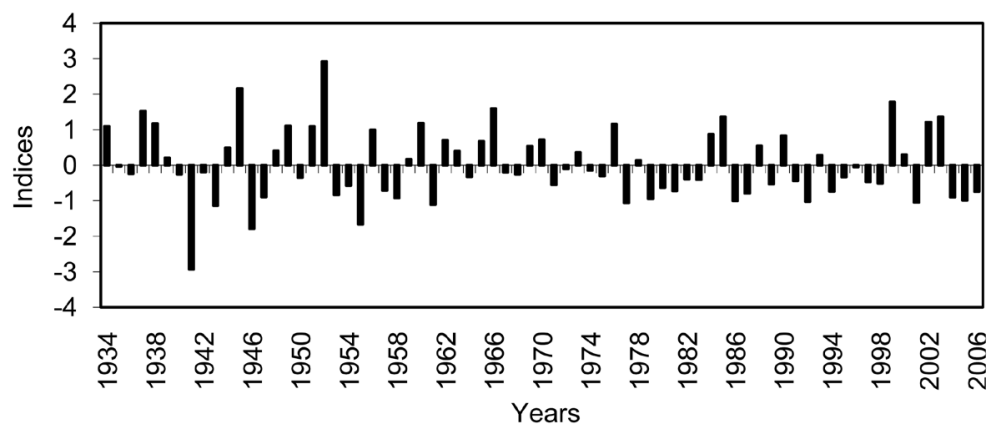

(d)

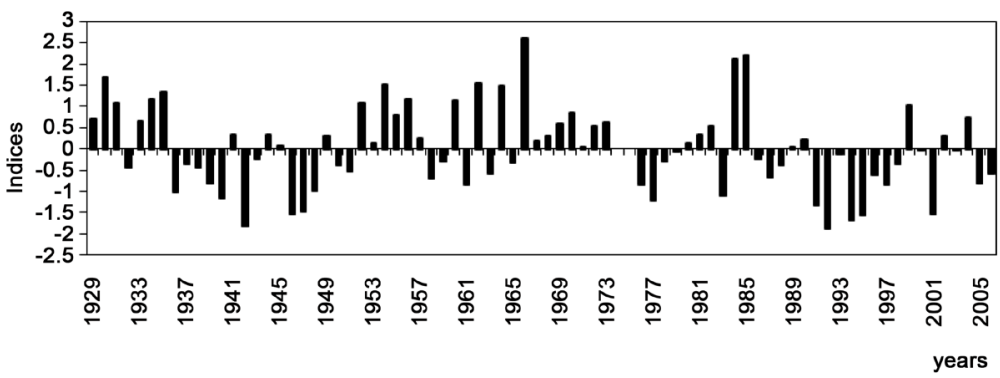

(e) 


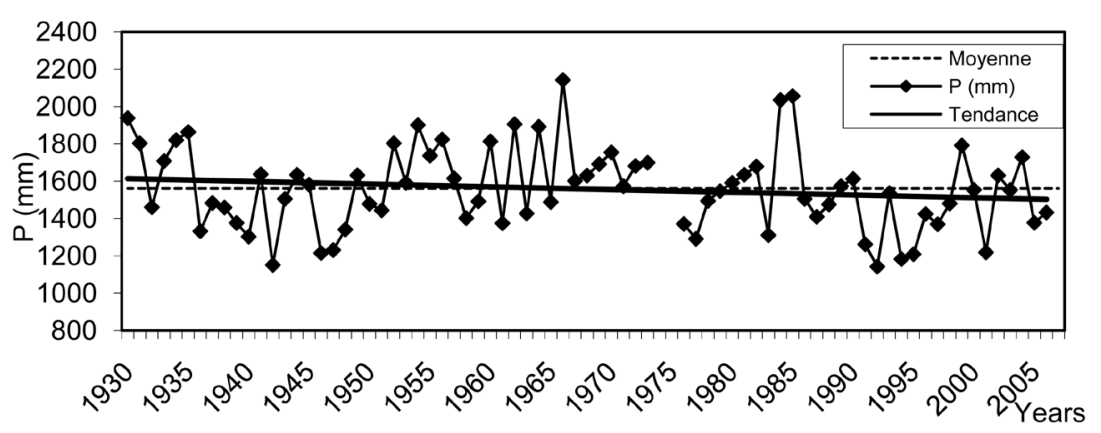

(f)

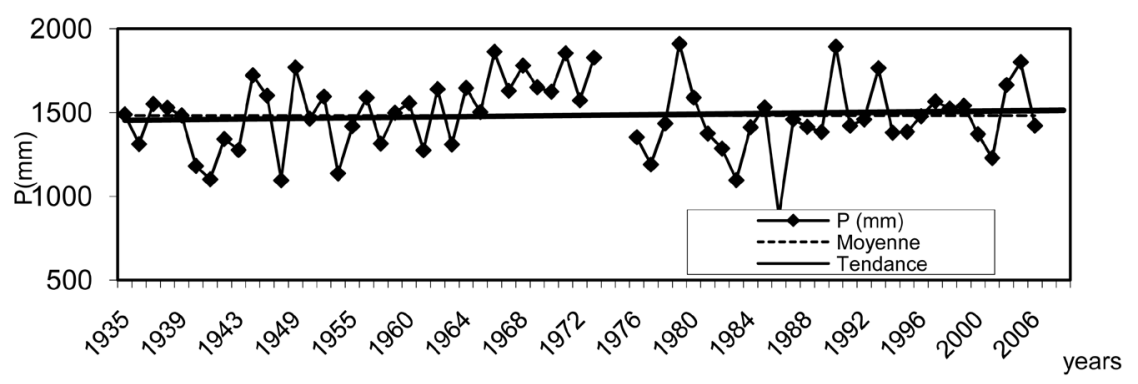

(g)

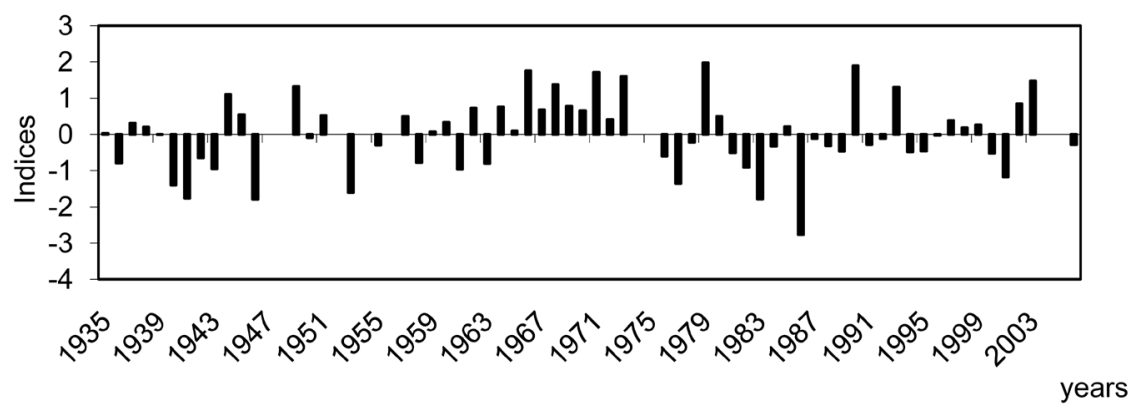

(h)

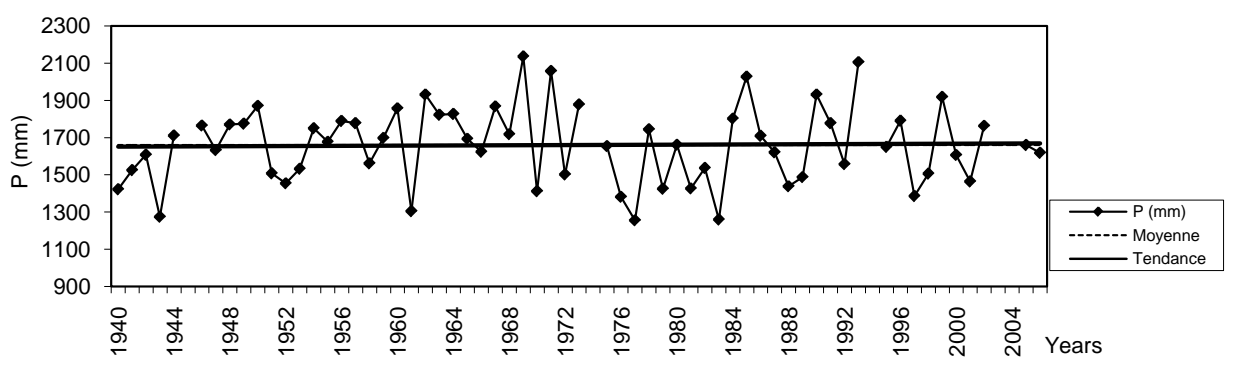

(i)

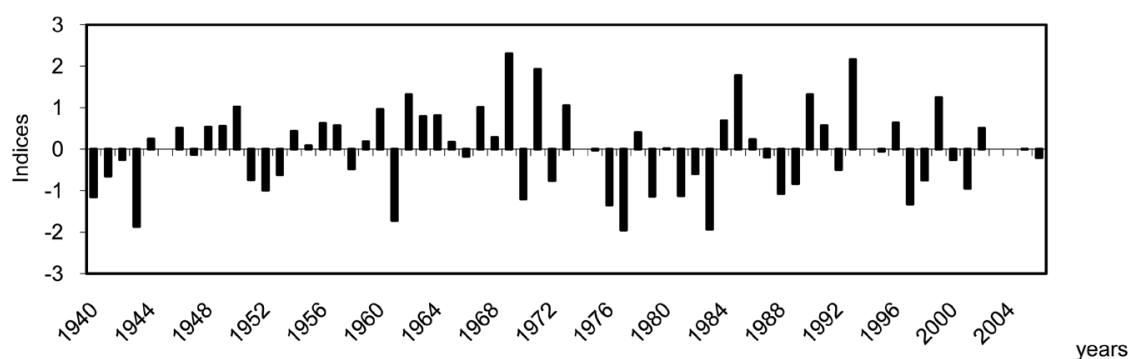




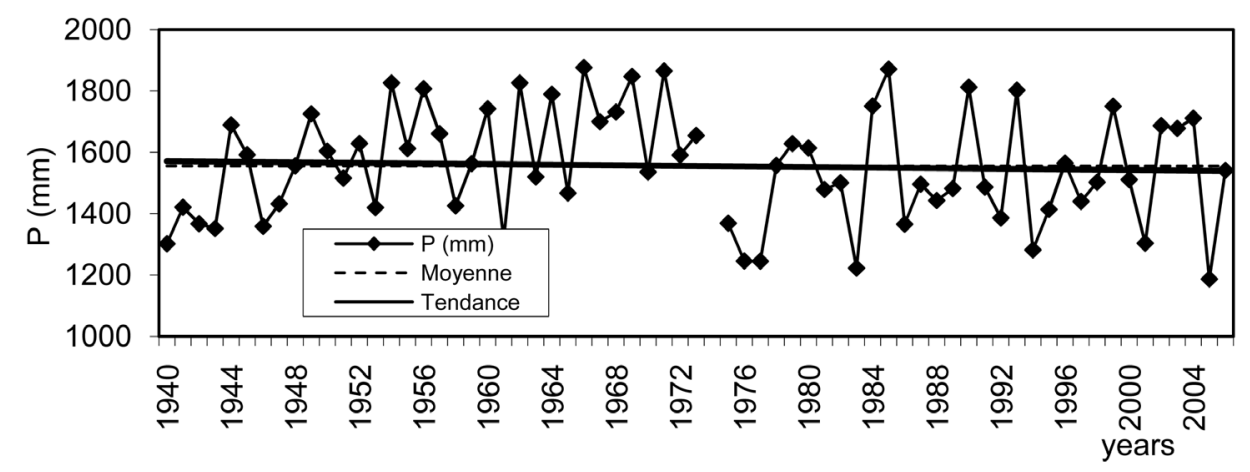

(k)

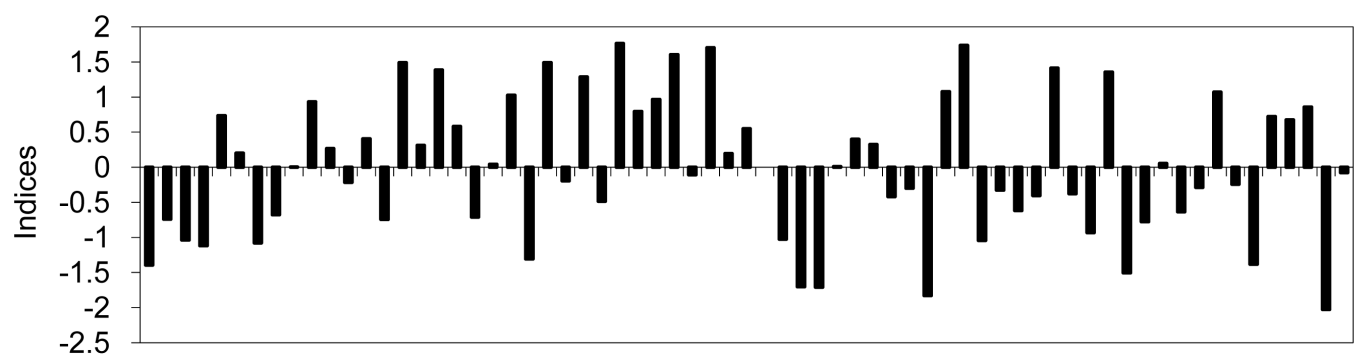

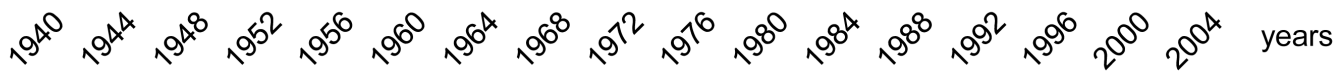

(l)

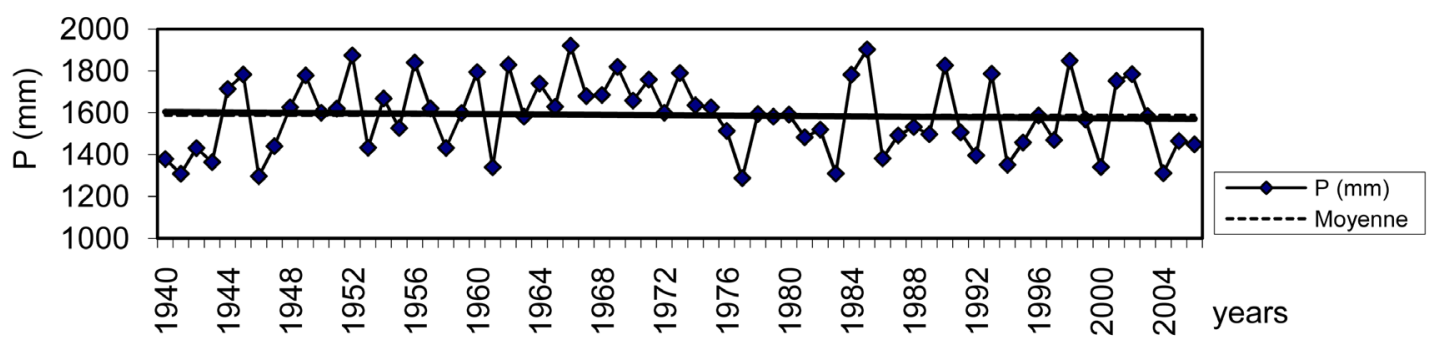

(m)

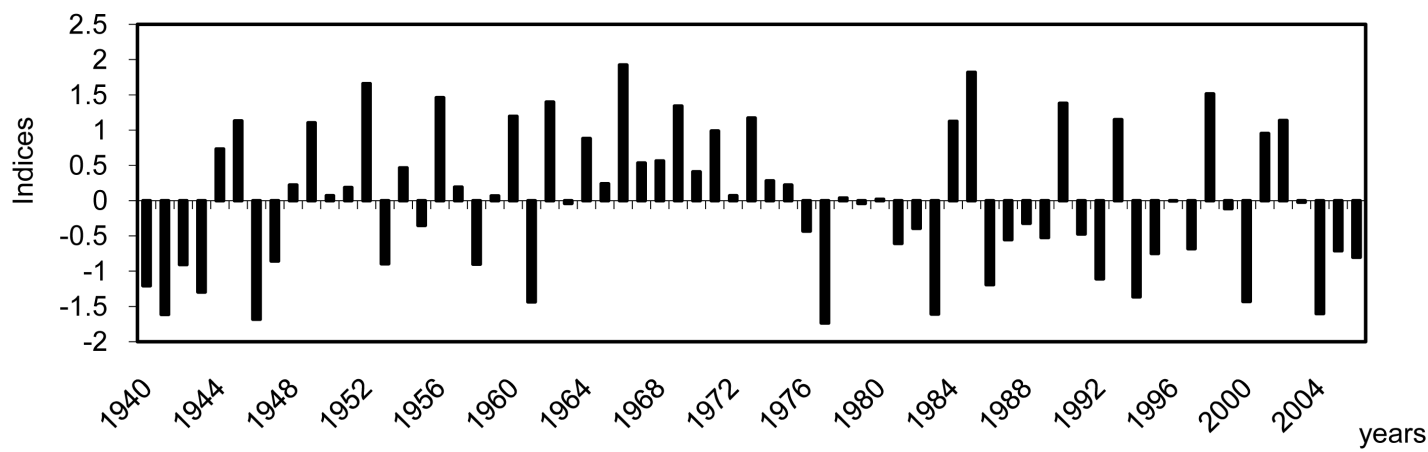

(n)

Figure 2. (a) variation in annual rainfall of Eséka station; (b) Variation in annual rainfall indices of Eseka station; (c) Variation in annual rainfall of Sangmélima station; (d) Variation in annual rainfall indices of Sangmélima station; (e) Variation in annual rainfall of Yaounde station; (f) Variation in annual rainfall indices of Yaounde station; (g) Variation in annual rainfall of Akonolinga station; (h) Variation in annual rainfall indices of Akonolinga station; (i) Variation in annual rainfall of Abong mbang station; (j) Variation in annual rainfall indices Abong-mbang station; (k) Variation in annual rainfall of the sub basin of Mbalmayo; (l) Variation in rainfall indices in the sub basin of Mbalmayo; (m) Variation in annual rainfall in the sub basin of Olama; (n) Variation in rainfall indices in the sub basin of Olama. 


\subsection{Evolution of Nyong Flow Rates}

The comparison of monthly decennial flows rates to those of period 1998-2006 gives the following trends:

-During the decade 50, the flow rates of the months of March, April, May and June were higher than the period 1998-2006. For cons, the months of July, August and September have rather lower rates than in the period 19982006 and for the months of October, November, December, January and February, the flow rates of the two periods are relatively confused.

—All flow rates of the decade 60 are higher than in the period 1998-2006 without exception.

- The flow rates of the 70s show a similar trend to those of the 50 decade except the months of October and November have rather higher speeds than in the period 1998-2006.

The confrontation decennial rates than the period 1998 -2006 to Olama station shows that the rates change as follows:

— The flow rates of the decade 60 are higher than in the period 1998-2006.

-During the 70s, the months of February, March, April, May and June have rates higher than those of 1998-2006, the months of July and August experiencing growth rates during the period 1998-2006. The months of January and February were relatively confused rates. Confrontation of flow characteristics of the period 19511977 and those for the period 1998-2006 shows that the flow rates of the 1998-2006 period are all without exception lower than in the period 1951-1977 to the Mbalmayo station. This also applies to the Olama station where the characteristics of the 1998-2006 period rates are lower than in the period 1965-1977 (Figure 3).

\section{Discussion of Results}

Several studies have focused on the impact of climate change on water resources; [2] [12]-[17]. Unanimously, researchers agree on the reduction or deterioration of water resources. In [18] climate variability also affects the stability of the infrastructure. Therefore, we must adapt infrastructure to local ecosystems. Reduced rainfall and lower flow rates recorded in the Nyong River have been reported worldwide. In China, it is much more pollution of rivers and watertable [19]. In the Polar Regions is melting glacial ice [15]. The filling of lakes like the Lake City Yaoundé or disappearance of Lake Chad is also irrefutable evidence of the impact of climate change on
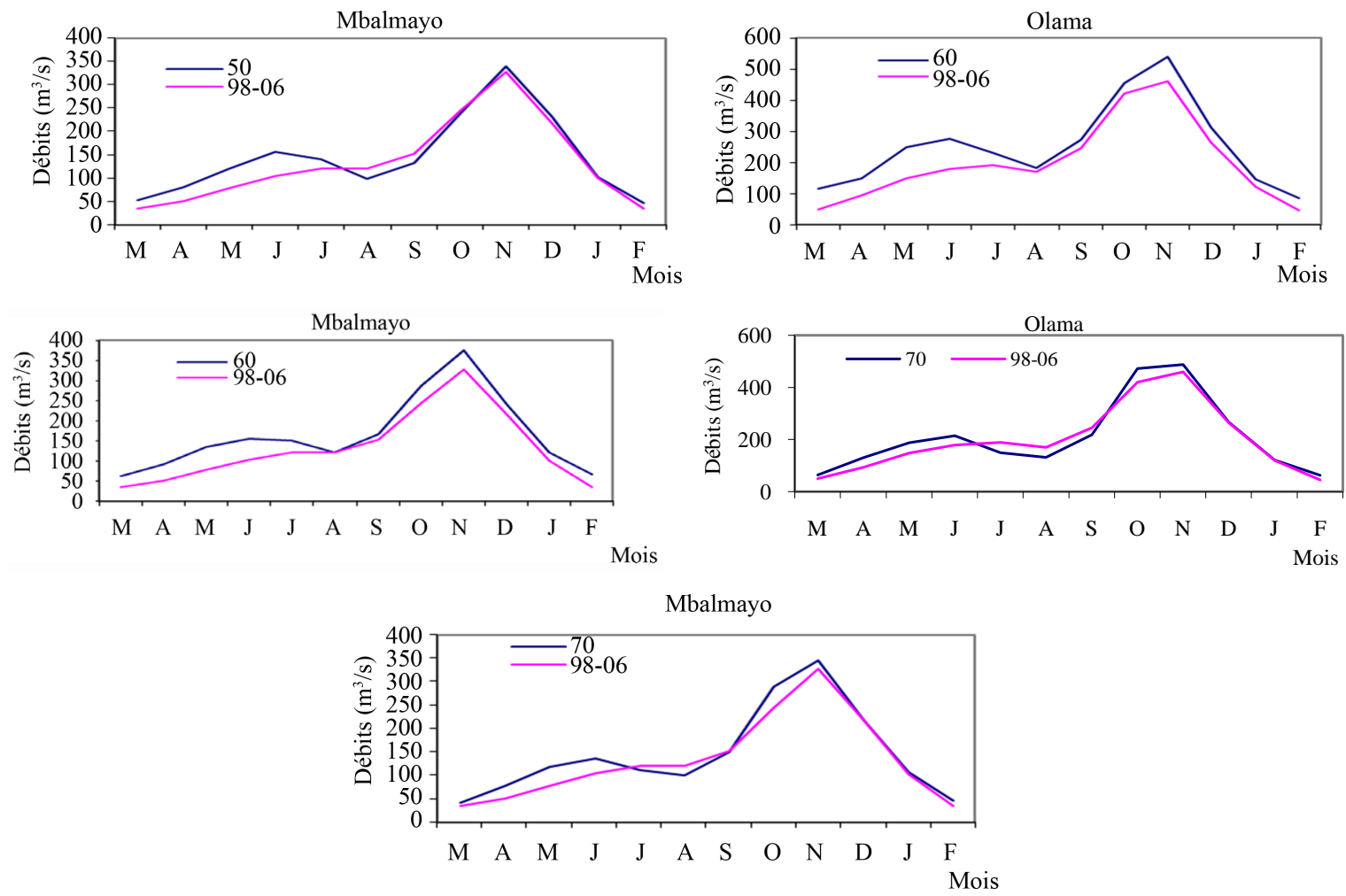

Figure 3. Evolution of Nyong flow rates in decades. 
water resources [20]. In the Nyong basin the impact of climate change materializes in lower flow rates and precipitation. The simultaneous decrease in rainfall and flow rate in the Nyong basin is inconsistent with the findings of [21] on the pool Amazon where climate variability is to affect the synchronous increase in rainfall and flow rate. This result is partly consistent with the work of [22] in the Sahel where there is a decrease in precipitation and increases in flow rate.

\section{Conclusion}

The analysis of rainfall and hydrometric data confirmed the general decline of rainfall and flows observed in tropical Africa in the Nyong basin. This decline is characterized by the decrease in the annual cumulative rainfall. The variability of hydrometric parameters is also manifested by an overall decrease but not uniform in monthly rainfall as well as the annual number of rainy days. Declining rainfall contributed to the decline in flows rate in Nyong River. The curves of the current monthly average flows rate in Nyong river have a look to unimodal trend (for the period 1998-2006) which is characteristic of tropical climates while the Nyong flows rate entirely in the equatorial zone unlike those of the period 1951-1977 which are bimodal and that normally characterize the equatorial climate. So we tend to think of the evolution of equatorial climate to tropical climate. The lower flows have a consequence of declining water resources of the basin Nyong which creates an imbalance between supply and demand for drinking water Yaounde and its environs. The bringing up of a new method of management of water resource according to the water supply of the population of Yaoundé may be conceived.

\section{References}

[1] Samba, A. (2015) Geotechnical Characterization of Alluvial Clays of the Nyong Valley Area Akonolinga. Afrique Science, 11, 262-268.

[2] Bineli, E. (2009) Impact of Climate Variability on Water Resources of the Nyong Basin. Mém. DEA. FAC.Sc. UYI., $82 \mathrm{p}$.

[3] Ndam, J. (1997) Hydrogeochemical Balance Sheets under the Tropical Forest River Systems Nyong and Sanaga South Cameroon. Th. Doc., Université Pierre et Marie CURIE, Paris, 214 p.

[4] Paturel J.E., Servat, E. and Kouamé, B. (1996) Out of Identification Procedures in Time Series Changing Rainfall Patterns in Africa Not Sahelian West. Pub. AISH, No. 238, 99-110.

[5] Servat, E., Paturel, J.E., Kouamé, B. and Lubes-Niel, H. (1998) Different Aspects of the Rainfall Variability in West Africa and Central. Journal of Water Science, 12, 363-370.

[6] Sighomnou, D. (2004) Analysis and Redefinition of Climatic and Hydrological Regimes of Cameroon: Evolution Perspective of Water Resources. Th. Doc. Etat, University of Yaoundé I: Accueil, 289 p.

[7] Hubert, P., Carbonnel, J.P. and Chaouche, A. (1989) Segmentation Hydrometeorological Series. Application of series of precipitation and West Africa Rates. Journal of Hydrology, 10, 349-3.

[8] Pettit, A.N. (1979) A Non-Parametric Approach to the Change Point Problem. Applied Statistics, 28, 126-230. http://dx.doi.org/10.2307/2346729

[9] Savané, I.(2001) Climate Variability and Groundwater Resources in Semi-Mountainous Region of Man. Bull. Sécheress, 12, 231-237.

[10] Moron, V. (1994) Rainfall Variability in Tropical Africa North of the Equator (1933-1990) and Relationships with Sea Surface Temperatures and Atmospheric Dynamics. Th. Doc. Climatology Research Centre, University of Burgundy, Dijon, 219 p.

[11] Kouakou, K.E., Goula Bi Tié, A. and Savane, I. (2007) Impacts of Climate Variability on Surface Water Resources in the Humid Tropics: Case Comoé Transboundary Watershed (Ivory Coast Bourkina Faso). Publ. Inc., Vol.16, No.1, 3143.

[12] Kenneth, F. (1997) "Water Resource and Climate Change” Resource for the Future. Washington DC. Climate Change, 37, 7-23.

[13] Nijssen, B., O’Donneld, G.M., Alan, F. and Deunis, P. (2001) Dialogue on Water and Climate 2002; Coping with Impact of Climate Variability and Climate Change in Water Management. "Hydrologic Sensitivity of Global Rivers to Change”. Climatic Change, 50, 396 p.

[14] Kabat, P. and Van Schaik, H. (2003) Climate Change the Water Rules: How Water Managers Can Cope with Today's Climate Variability and Tomorrow Climate Change. World Water Assessment Programme. World Water Development 
Report. UNESCO, Paris.

[15] Goldie, A. (2006) Global Warming and Fluvial Geomorphology. Geomorphology, 79, 384-394.

[16] Nigel, A. and Gosling, S. (2013) The Impact of Climate Change of Climate Change on River Flow Regimes at Global Scale. Journal of Hydrology, 486, 351-364.

[17] Lienou, G. (2007) Impacts of Climate Variability on Water Resources and Transport of Suspended Matter of a Few Representative Watersheds Climate Units in Cameroon. Th. Doc. Etat, University of Yaoundé I, 362 p.

[18] Zo'o Zame, P. and Samba Assomo, P. (2015) The Influence of Climate Factors on the Stability of Infrastructures: Case of Forest Ecosystem in Southern Cameroon. International Journal of Geoscience, 6, 1317-1322.

[19] Dou, L. and Li, T.T. (2015) Regional Geochemical Characteristic and Influence Factors Soil Elements in the Pearl River Delta Economic Zone, China. International Journal of Geoscience, 6, 593-604.

[20] Oumar, B., Ekengele, L. and Balla, A. (2014) Evaluation of the Level of Pollution by Heavy Metals Bini Dang and Lakes in the Region of Adamawa, Cameroon. Science Africa, 10, 184-198.

[21] Tardy, Y., Mortatti, J., Ribeiro, A., Victoria, R. and Probst, J.L. (1994) Fluctuations in Rainfall, Flow and Temperature in the Amazon Basin and Oscillations of the Global Climate over the Past Century. C.R. Acad. Sci. Paris, t. 318, Série II, 960-995.

[22] Diello, P., Mahe, G., Paturel, J.S., Karambiri, H. and Servat, E. (2005) Reduced Rainfall and Increased Flows in the Sahel Relationship between Hydrology, Soil Degradation and Population Dynamics. Seminar Abstract of Program. 